\title{
Correction to: Australian experience with robot-assisted Roux-en-Y gastric bypass with comparison to a conventional laparoscopic series
}

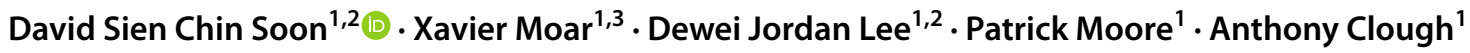

Published online: 7 October 2021

(c) The Author(s), under exclusive licence to Springer Science+Business Media, LLC, part of Springer Nature 2021

\section{Correction to: Surgical Endoscopy}

https://doi.org/10.1007/s00464-021-08723-4

This article was updated to correct an error in author affiliation 1.

Publisher's Note Springer Nature remains neutral with regard to jurisdictional claims in published maps and institutional affiliations.

The original article can be found online at https://doi.org/10.1007/ s00464-021-08723-4.

David Sien Chin Soon

davidsoon1991@gmail.com

1 Department of General Surgery, Epworth Richmond, 89

Bridge Road, Richmond, VIC 3121, Australia

2 Department of General Surgical Specialties, Royal

Melbourne Hospital, 300 Grattan St, Parkville, VIC 3050, Australia

3 Department of General Surgery, St Vincent's Private Hospital, 22-36 Scott St, Toowomba, QLD 4350, Australia 